\title{
Personalization of Legal and Ethical Information in ICT Platforms: The Approach of Legal Decision Tree
}

\author{
Adnan Imeri ${ }^{1}$, Abdelaziz Khadraoui ${ }^{1}$, Thang Le $\operatorname{Dinh}^{2} \&$ Djamel Khadraoui ${ }^{3}$ \\ ${ }^{1}$ Institute of Service Sciences, University of Geneva, Geneva, Switzerland \\ ${ }^{2}$ Université du Québec à Trois-Rivières, Trois-Rivières, Canada \\ ${ }^{3}$ Luxembourg Institute of Science and Technology(LIST), Luxembourg \\ Correspondence: Adnan Imeri, Institute of Service Sciences, University of Geneva, Battelle Bat. A, Route de \\ Drize 7, 1227 Carouge, Geneva, Switzerland. Tel: 41-223-790-119. E-mail: adnan.imeri@unige.ch
}

Received: January 15, 2017

Accepted: February 4, 2017

Online Published: February 9, 2017

doi:10.5539/cis.v10n1p77

URL: http://dx.doi.org/10.5539/cis.v10n1p77

\begin{abstract}
This paper aims at presenting a theoretical approach for the representation of legal and ethical information in a personalized way in ICT platforms. The personalization process allows us to adapt the legal information for endusers of ICT platforms. This approach points out the key element for defining a complete legal and ethical corpus of documents. Based on the corresponding scenario, the legal information is selected, filtered and then presented in ICT platforms. For organizating and analyzing this legal and ethical information, we reuse the existing notion of the decision tree and enhance it with a set of legal parameters emerging from legal documents. This legal decision tree will help us to treat different types of legal cases, which may relate to different service scenarios.
\end{abstract}

Keywords: personalization, legal information, ethical issues, legal decision tree (LDT)

\section{Introduction}

While we are defining service scenarios (Note 1) of development an information and communication technologies (ICT) platform (Note 2), there are several actions that should be taken into account. These actions are required to guarantee that their related service scenarios must comply with several regulatory frameworks including legal and ethical issues as well as, the general standard and international norms (Imeri \& Khadraoui, 2015). The intention of considering the legal and ethical issues is stemmed from the need of organizations to ensure more transparency while performing activities through their ICT platforms (Turki \& Bjekovic-Obradovic, 2010). There are several recommendations to consider the scenario development by processing both the legal and ethical issues in an early stage of development by using a methodological approach in order to validate these scenarios (Imeri \& Khadraoui, 2015; Imeri et al., 2016). Ignoring or neglect the legal and ethical issues may lead to project failure; therefore, the damage in market value could be considerable based on the previous experiences (Shazia \& Governatori, 2010).

We propose hereafter a strategy, which initially allows us to explore and select legal and ethical sources, from which we can formulate a corpus of legal documents. This formulation of legal and ethical documents is based on a scenario description and represents a context in which there are several situations needed to be considered in order to provide a complete coverage of legal and ethical information (Note 3) (Bratcher et al., 2005). For covering all possible cases stemmed from a scenario situation context, we organize these legal and ethical documents (Note 4) in a form of a tree, which is based on the most highlighted parameters, e.g. work contract activity: as paid or unpaid, the age of a person, etc..The organization of legal and ethical documents allows us to explore any possible situation, which stems from the context of the scenario where the legal and ethical issues should be considered. Based on this tree-based structure, we can further make an analysis on legal and ethical documents, then personalize the legal and ethical information for each end-user by using technical components.

This personalization is carried out based on the scenario context and end-user profile, by performing a matchmaking (Note 5) between them. The personalization process (Note 6) provides a content of legal information for end-users of ICT platforms. The content of information, which we offer by the personalization service, are "General Legal Rules", "Restrictions", "Obligations", "Recommendations" and "Precautions" and 
also the whole legal source to consider. This information showed to the end-users will be selected based on the context of scenario and the end-user profile matching, e.g. if the end-user has the age over 65, the content of legal information will be different with an end-user who has the age less than 65, and this is because of different legal issues to consider for this possible scenario.

Besides representing the structured legal information organized as legal rules, this approach enables to show all the legal documents related to a scenario. In this sense, it allows end-users of ICT platforms to explore the whole legal content.

Giving the significance of displaying the legal information in real time will facilitate the work of legal officers or even end-users in the decision-making process for any further action in ICT platforms.

The research presented in this paper is carried out for a real case development project in context of an European project in the domain of Ambient Assisted Living (AAL). "This project aims at developing an ICT platform that allows posting, browsing and exchanging basic information between competence offering seniors and search-based requests, from competence demanding organizations from the public, private and voluntary sectors" (Imeri et al., 2016).

Furthermore, this paper is a continuous work from our last research paper (Imeri et al., 2016), whose intention was to propose a methodology for developing scenarios in compliance with legal and ethical issues. In this paper, we make a step forward by using another methodology approach that allows us to personalize the legal information for any possible activity of scenario and show this information for the end-users of an ICT platform in a real time. Based on the functionality of this ICT platform, we will use several scenarios in order to support our approach.

This paper is organized as follows. Section 1 describes the context and the related work related to personalization process of the legal and ethical information. Section 2 presents our methodology approach for personalization of legal and ethical information. Subsection 2.1 introduces the process of gathering the legal and ethical documents, and Subsection 2.2 shows the organization of these documents. Subsection 2.3 continues with some technical component for developing personalization service based on legal decision tree approach, and Subsection 2.4 describes mainly the personalization mechanisms. Section 3 presents an example, which demonstrates the application of our methodology, and finally Section 4 shows conclusion and future works.

\subsection{Related Work}

Nowadays, the availability and utilization of legal information resources as determinants of legal professionals in the business environment. Actually, traditional contents (e.g. law books, legal periodicals, reference materials, legislation, etc.) were readily available to legal lecturers; however, E-resources and online legal databases were less available (Uluocha \& Mabawonku, 2014). For this reason, there is an urgent need for the models and methods to integrate new digital resources into current information systems so that end-users of business systems can use this information in real time.

Research studies related to the integration of legal information into information systems can be classified into the following categories: artificial intelligence based, ontology-based, knowledge-based and location-based approaches.

Artificial intelligence-based approaches focused on the attempt of relating the different elements of a legal decision and then of constructing a framework for discussing legal information systems as a part of the decision process (Bing, 1984). Another approach of this category used the combination of symbolic and connectionist artificial techniques for legal information retrieval (Rose \& Belew, 1989).

Ontology-based approaches used the ontology to deploy the legal information systems in order to facilitate the management, searching and sharing legal content (Gómez-Pérez et al., 2006). Ontologies can assure the role of explicit specifications of domain's conceptualisations in legal information systems (Bench-Capon \& Visser, 1997). Some large and public ontologies, such as Wordnet, have also been used to build legal information systems that can fit the cross-lingual information retrieval needs of both legal professionals and nonprofessionals (Dini et al., 2005).

Knowledge-based approaches used different knowledge management techniques and tools to build intelligent legal information systems (Zeleznikow \& Hunter, 1994). One approach of this category worked on the construction of intelligent legal decision support systems in discretionary domains in order to enhance consistent decision-making (Zeleznikow, J. (2000). Another approach focused on a basic unit of reasoning of a legal system that supports the construction of arguments and drafting of determinations in laws (Yearwood \& Stranieri, 1999). 
Location-based approaches aim at providing a location-based legal information servin which hich a subscriber to the service is assumed to have a data device and the location of the data device is determined through a positioning system. Thus, legal information is then retrieved, such as a law or a regulation that is applicable to regulating or restricting activities at or near the determined location (Dutta \& Zachariah, 2002).

On the other hand, ethics is important in the Information Systems (IS) field as illustrated by the direct effect of the new laws (such as Sarbanes-Oxley Act on the work of IS professionals); however, there is not much of this work is carried out yet (Mingers \& Walsham, 2010).

According to our observation, the proposed approach in this paper is one of the first that focuses on managing both legal and ethical information based on the perspective of service scenarios. The purpose of this research is to provide a context-based information for nonprofessional users in real time to assist them in improving their business decisions.

\section{Methodology Approach}

The missing of the implementation of the legal and ethical information in real time in ICT platforms leads to the situation, in which the decision makings having legal issues to consider may create a process vague and uncertain for end-users. Our approach aims at solving this problem by providing a set of legal and ethical information for end-users of ICT platforms in real time. This approach allows end-users to interact with ICT platforms for fulfillment of legal and ethical requirements.

Our approach is composed of four steps:

1. Selection of legal documents based on scenarios;

2. Organization of legal documents by a legal decision tree (LDT);

3. Technical implementation of the legal decision tree; and

4. Development of mechanisms to present legal content in real time.

In the following, we will introduce in details those steps by presenting their composition at the design level.

\subsection{The Procedure for Composing the Legal Document Corpus}

In our approach, the first step is the selection of the legal and ethical documents. The set of legal and ethical documents is composed based on scenario specifications. We consider that a single scenario involves one or several activities (Imeri et al., 2016). For some activities, there is a need to consider the legal or ethical issues. Each activity then can have several sub-activities, which also may have legal and ethical issues to consider.

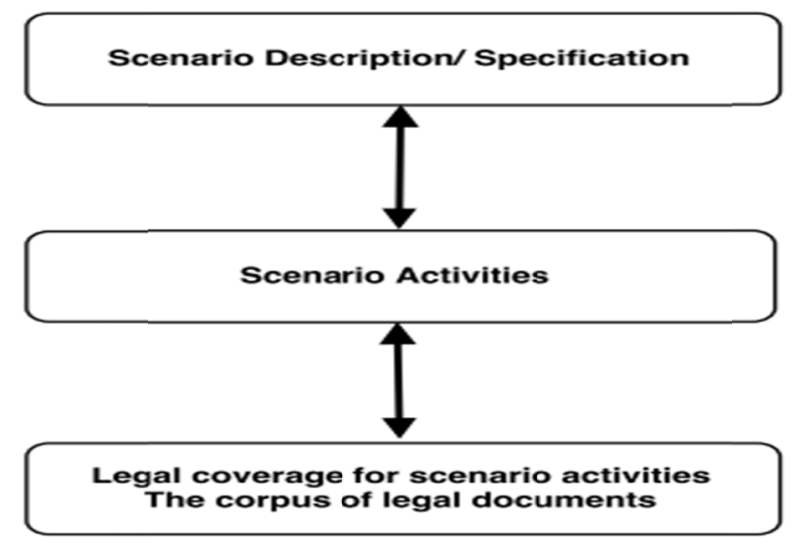

Figure 1. The process of composition the legal corpus

Examining all these situations, we proceed with the selection and classification of legal documents in order to cover all the activities of scenarios with legal and ethical information. Figure 1, presents conceptually the process for formulating the corpus of the legal documents.

For example, in order to elaborate the process described in Figure 1, supposing that we have a specification of a scenario for "a paid work activity for a person with age less than sixty-five". Since the activity is paid, we consider the legal framework documents for the employment contract, work permit for a person, work place assurance, health assurance, etc. In this sense, we compose the corpus of legal documents for the case of paid work activity. This is the basic step that will be followed by the next step, which organizes these documents by 
using the notion of a legal decision tree.

\subsection{Organization of Legal Documents by a Legal Decision Tree (LDT)}

Just after having the corpus of legal documents for a particular scenario, we proceed with the organization of the legal documents by using the notion of a legal decision tree (LDT). In this Section, we will explain the notion of a decision tree, then present the conceptual model that can be used for composing the legal decision tree.

\subsubsection{The Notion of a Decision Tree}

A decision tree shows a classification of models based on the form of the tree structure. Using the decision tree, we can decompose the set of data, and in this way, we show the most important factors in the data sets that make the tree increase continuously (Victor, 2001; Quinlan, 1986; De Ville \& Neville, 2013). In a decision tree, we have two types of nodes, a decision node or a root node. Each node has two or more subsidiary nodes and leaf nodes that represent the classification (Quinlan, 1986; De Ville \& Neville, 2013). An example of the decision tree is presented in Figure 2, where "Legal Decision Tree $\mathrm{CH}^{2}$ is a root node and "Paid Activity" and "Unpaid Activity", are leaf nodes.

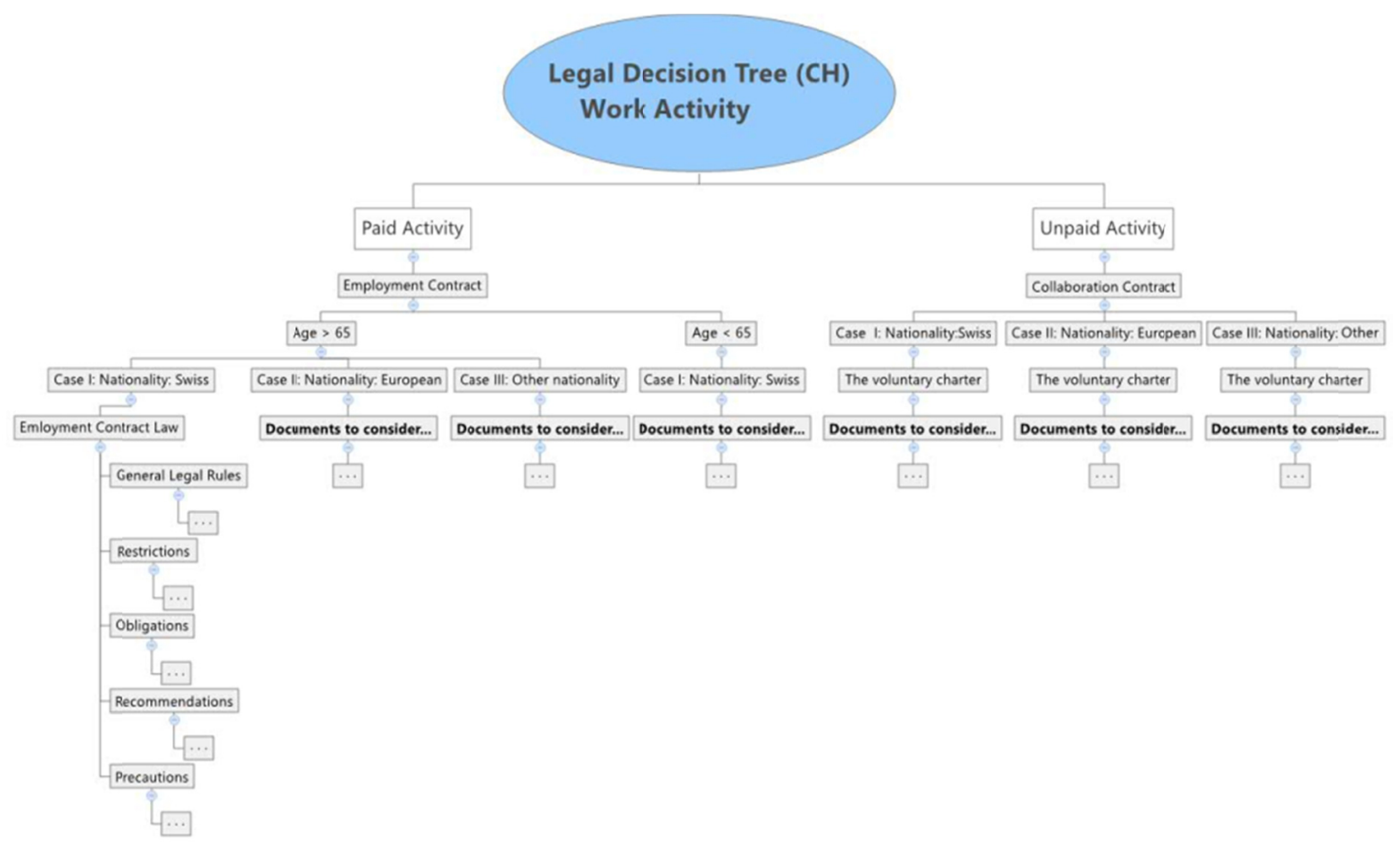

Figure 2. An example of a decision tree for the case of Switzerland regulatory framework

Subsequently, we will present the conceptual model, which is the base to develop the legal decision tree (LDT) with its main elements of LDT.

2.2.2 Conceptual model to support the Legal Decision Tree (DLT)

As a base for developing the legal decision tree, we use the existing meta-model defined in previous research studies from Imeri et al. (2016) as presented partly in Figure 3. In this meta-model, we have the main component "SCENARIO", which is linked to the component "ORGANIZATIONAL CONTEXT". It means that: For each scenario, we have, an "ORGANIZATIONAL CONTEXT" that, includes its instance components such as "Regulation and Laws", "Ethical Issues" and "Standards and International Norms". This relation determines that, for any possible scenario, we should consider the components of "ORGANIZATIONAL CONTEXT", whose instances ensure the compliance of any "SCENARIO" and its activities. Through this model, we have the opportunity to select each defined scenario and then to analyze the legal and ethical issues as we have mentioned in Imeri et al. (2016). In this context, we develop the legal decision tree to help us to determine each possible case stemmed from the scenario specification, to be treated by laws and ethical principles. 


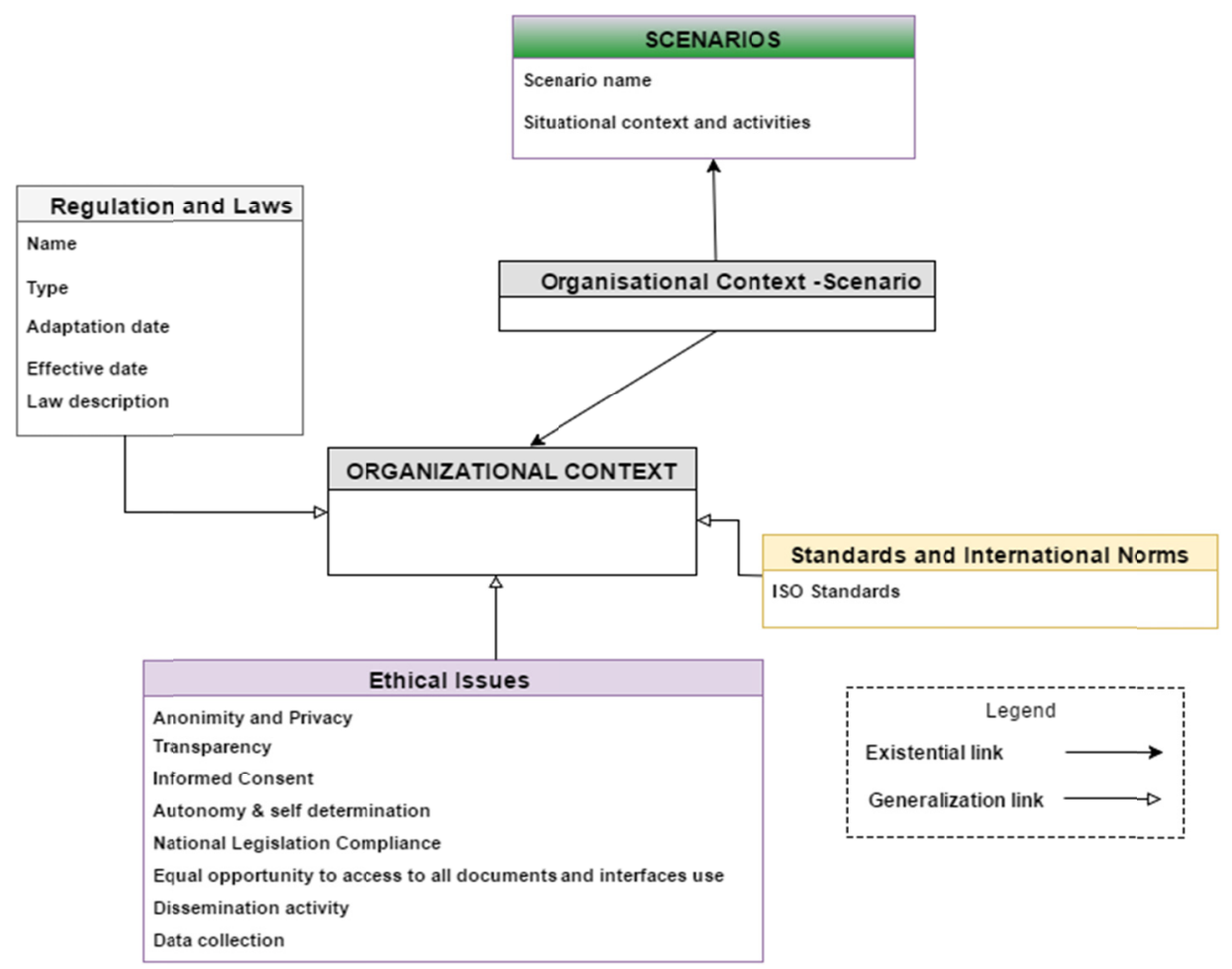

Figure 3. The meta-model as a base for developing legal decision tree (LDT) (Imeri et al., 2016)

The notion of legal decision stems from the set of nodes, which contain the parameters comes from legal documents and are significant to determine the legal content to be considered. The legal decision tree intends to cover all possible situations emerges from the scenario analysis with legal and ethical issues. This process allows us to compose a huge set of data organized in form of a tree whose nodes are deterministic for legal document organization in favor of legal and ethical coverage of scenarios. For example, if we refer the example presented in Figure 2, we have a situation in which the "work activity" can be a paid or an unpaid activity. Then, this situation is defined on the tree nodes where one branch of the tree shows the set of documents for a "paid activity", while the opposite branch of the tree shows the set of documents for "unpaid activity", as showed in Figure 2. In case we decide to select the "paid activity" and following the tree structure, we have "Employment Contract" as a component that determines the "paid activity".

Then, we have "General Legal Rules" which determine the main legal rules for employment contract activities. Subsequently, we have benches of the tree which shows the "Restriction", which should be respected in case of an employment contract. The tree branch for "Obligations" determines the set of obligation emerged from laws, and it should be respected in case of an employment contract. While the branches for "Recommendations" and "Precautions" are the set of rules, which originates from ethical principles.

Apparently, through the legal decision tree, we consider the coverage of all activities from the scenario specification with legal and ethical information.

Defining and organizing this information requires an analysis process of laws and ethical documents. Based on the analysis of laws and ethical issues associated with scenarios, the most significant parameters to consider in the tree nodes can be detemined and these sets of rules for the personalization of legal information in real-time into ICT platforms, can be formulated. The rule composition and interpretation can be carried out in collaboration with legal officers.

\subsection{Technical Implementation of Legal Decision Tree}

For the technical implementation, we, firstly, begin with the global architecture of the personalization service. The intention of presenting the global architecture of the personalization service is to clarify the way in which the technical aspects are organized and operated. This service, which is developed based on traditional service-oriented-architecture (SOA) is composed of three main layers corresponding to Data Layer Guidelines (2016) and Buecker et al. (2008): 
Database layer,

Data access layer, and

User interface layer.

Figure 4 presents the three layers with their functionalities.

Layer's roles:

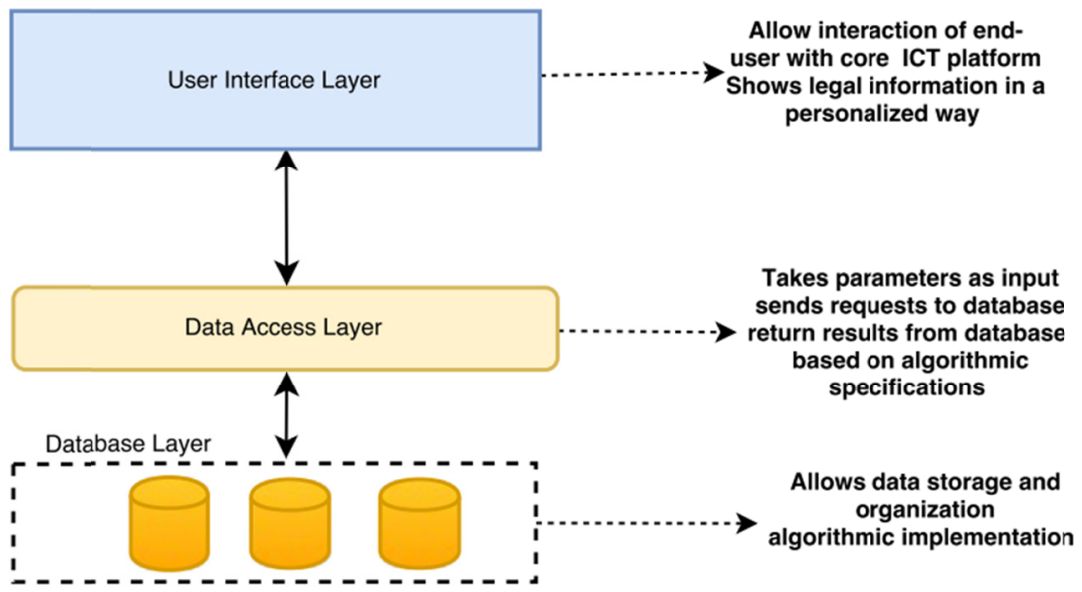

Figure 4. The architecture of personalized legal service (Buecker et al., 2008; Data Layer Guidelines, 2016)

Besides the organization of legal documents by the LDT tool, we continue to develop the technical components, which are required to support the implementation of LDT. The implementation of LDT is carried out in the backend side of the service. We organize these documents mainly in database tables. For assuring the data consistency, database diagrams relationship is used to model the relationships and to connect data tables. The main functionality of these database diagrams, for the purpose of LDT development, is to refer to the design-time functionality of meta-model showed in Figure 3, as an initial base to build these data table connections. In our approach, this model is enhanced to introduce other database objects, which then can be used to structure the legal information from the LDT.

Figure 5 presents the schema and its main elements, which are used for the implementation of the LDT based on database technologies.
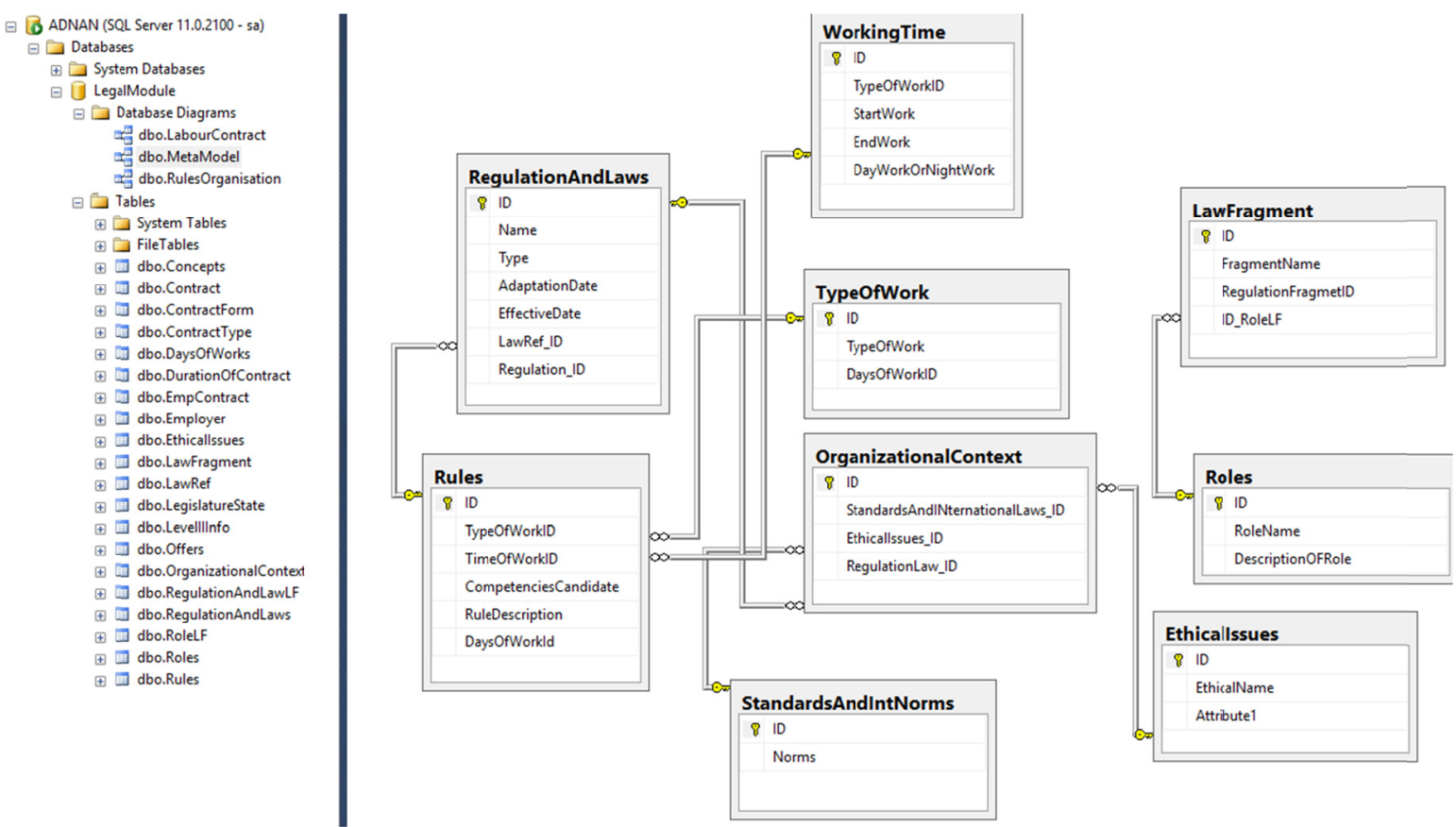

Figure 5. The main database objects for developing the LDT 
In order to illustrate this technical development, let's discuss about the development of technical components from LDT tool related to, the case of "paid activity", concretely the case of "Employment Contract". In the diagram presented in Figure 6, the main component is the "Contract" object, which is linked with objects "Duration of contract", which has attributes to define the duration of any possible working contract. The object "Contract Type" determines the types of contract, e.g. fixed term, temporary term, etc., then the form of contract is determined by the object "Contract Form" e.g. digital form or paper form. For each contract, we have the working time determined by the "Working Time Agreement" object. The object "TheWorkers" presents the end-users. Finally, the object "Legislature State" contains the main attributes to determine the legal rules related to contract elements.

In terms of the personalization, we have this information organized and presented based on profile of each end-user, e.g. The Worker, and the type of activities from the scenario. For instance, when a person, which has an age over than sixty-five, he or she has an opportunity to work as a teacher in a private institution. Since, the age is a retirement age, there are some legal constraints determined by "Employed contract". In this situation, the duration of contract has specific conditions; the working time agreement has several legal issues to consider, etc. In this context, the diagram showed below contain all these elements. We use these rules within the context of the personalization to notify end-users that several legal issues need to be taken into account in this case, by showing to them the related general legal rules, obligation, restrictions, recommendation, and precaution.

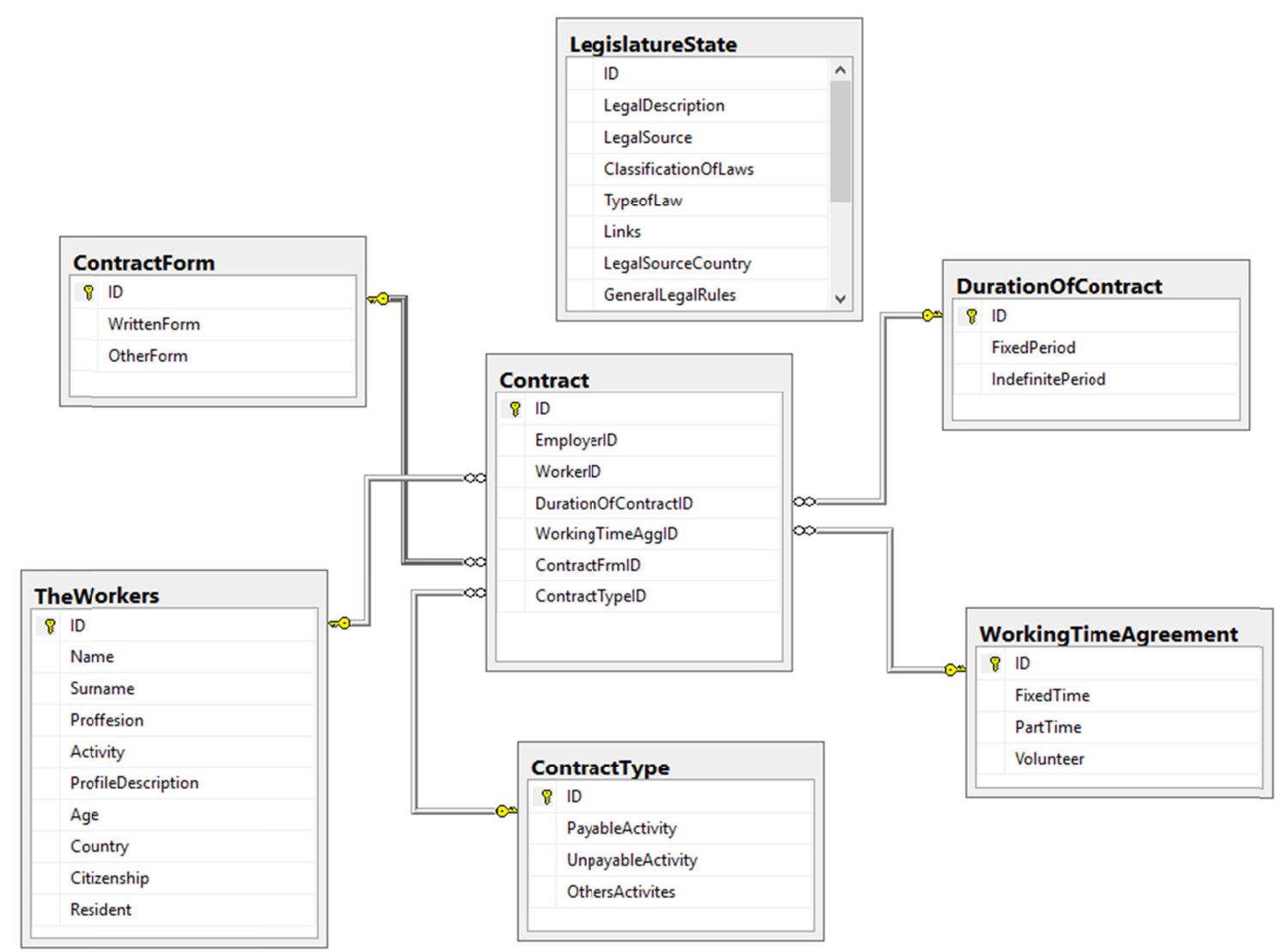

Figure 6. The developing of LDT for the case of "Employment Contract"

\subsection{The Mechanisms to Present Legal Content in Real Time}

For developing the personalization service, we use several technical mechanisms to enforce the process of personalization. These mechanisms are implemented by different algorithms to support this solution. Basically, the solution operates based on the parameters derived from the profile of the end-user (e.g. the Workers attributes, from Figure 6) and works in combination with activities from the scenario specification (e.g. paid work activity for a person with age higher than 65). It selects specific legal information from databases as illustrated in Figure 5 and Figure 6 and presents this information according to different layers of the user interface, as mentioned in Figure 4. 
Concerning the process of personalization of legal information, the mechanism of personalization is inspired from Adomavicius and Alexander (2005), and in our research context, there are several new concepts introduced in order to fulfill the personalization of legal information. Those concepts are presented in the sections above and elaborated by a global schema in Figure 7 .

In the context of personalization of legal information for end-users of an ICT platform, Figure 7 presents the process of personalization. The personalization service offers, in general, the content of legal and ethical information. The specified legal content is composed by "Service engineers" in cooperation with "Legal officers". This content is determined based on the scenario context by selecting basic elements that represent the most significant legal information that is important for end-users of an ICT platform. The end-users of the ICT platform are considered as consumers of this legal information. The main goal behind this personalization is to provide the legal information for the end-users of an ICT platform in real time in order to give them a specific set of legal information related to their selected activity. Thus, they can explore, and decide if their activities are in compliance or not before taking further actions, (e.g. applying for a job offer) through the ICT platform (Adomavicius \& Alexander, 2005).

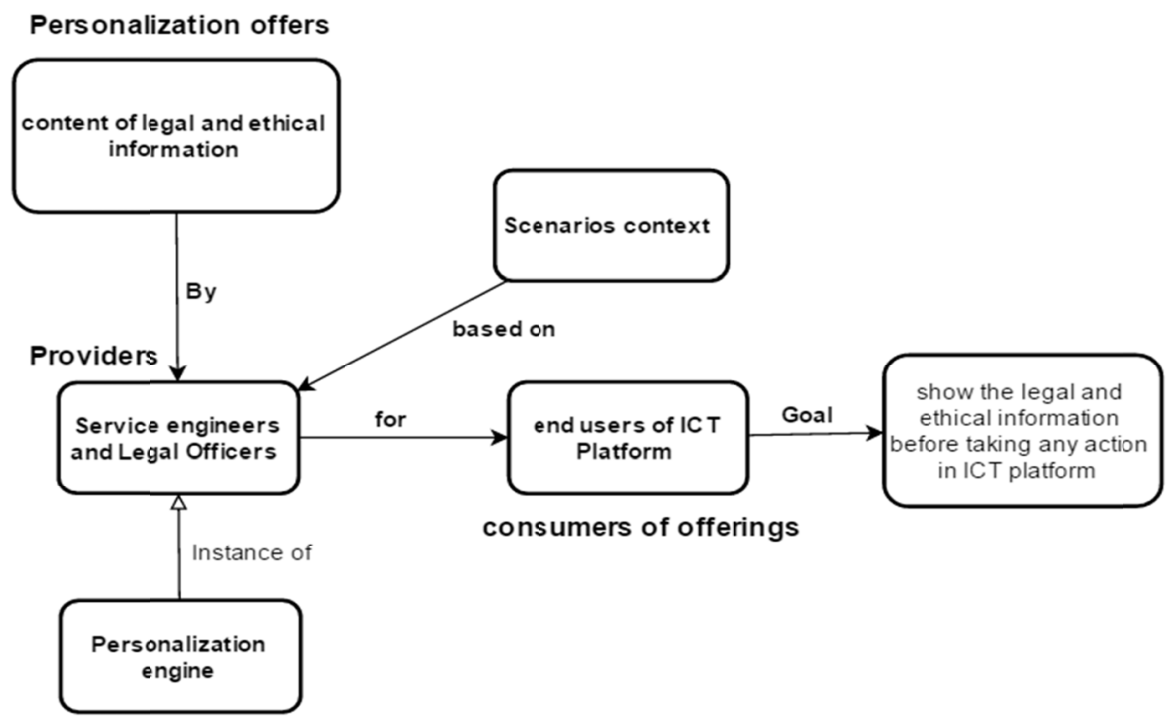

Figure 7. The schema representing the process of personalization of legal information inspired from Adomavicius and Alexander (2005)

\section{Illustrated Example}

This section illustrates through a practical example of the proposed approach for personalization of the legal and ethical information in ICT platforms. This example was inspired from our works done in the context of European project (http://sponsor-aal.eu/) in the domain of Ambient Assisted Living (AAL). The contribution of the research team, which is developed in this project, is focused on the needs and activities of the association that provides services to the people suffering of Alzheimer disease. The ICT platform is used by the association to acquire and manage people and other stakeholders interested to assume these services.

A complete legal decision tree is elaborated to illustrate various situations describing the legal constraints regarding employment, post-retirement activities and the volunteering activities.

\subsection{Selection of the Legal Framework Regarding Employment, Post-Retirement Activities}

In the case of employment or post-retirement activities, the relevant labour regulations in Switzerland should be selected and specified. The specification of legal requirements aims to ensure that the possible work contract will be in adequacy with the relevant legal framework and business rules. Labour regulations in Switzerland are subordinate to the Collective Labour Agreement (CLA) (Note 7). The basis of Swiss labour law can be found in the Code of Obligation and in the Federal Labor Act but there are other labour regulations to consider as mentioned below:

1) The Federal Labor Act (Note 8) (RS 822.11): the following topics are described in this law:

a. Provisions on health protection. 
b. Obligations of employers and workers.

c. Working time.

d. Working day and night work.

e. Medical examination and advice.

f. Special arrangements of protection.

2) Ordinance 1 of 10 May 2000 on the Labour Act (OLT 1) (Note 9) (822.111): this law clarifies these elements :

a. Working time.

b. Working day and night work.

c. Additional work. Terms and duration.

d. Medical examination and advice.

e. Special arrangements of protection.

3) Ordinance on admission, residence and the practice of a gainful activity (Ordinance142.201).

4) Free movement of persons with the EC and EFTA Member States (Ordinance 823.24).

\subsection{Selection of the Legal Framework Regarding the Volunteering Activities}

In the case of volunteering activies, we consider the European charter on the Rights and responsibilities of Volunteers (Note 10): "The European Charter of the Rights and Responsibilities of Volunteers creates a common understanding of the definition of volunteers, volunteering activities and volunteering providers from the local to the European level and provides a common set of basic rights for volunteers and volunteering providers" (Note $10)$.

Based on this document, we specified some ethical principles and legal rules and the volunteering providers (Associations), which uses ICT platforms should consider all these principles:

- Principle 1: Protection against all kinds of discrimination.

- Principle 2: Rights and responsibilities of the volunteer.

- Principle 3: The right to social protection during the volunteering activity.

- Principle 4: Right to support from volunteering providers the reimbursement of expenses.

- Principle 5: Every volunteer is entitled to support and feedback throughout the volunteering activity.

- Principle 6: Rights to personal development (educational/training support).

- Principle 7: The Recognition of the volunteering activities.

3.3 Organization of legal documents by a legal decision tree (LDT)

As described previously, the legal decision tree is developed to illustrate each potential situation identified from scenario specification, to be treated by laws and ethical principles.

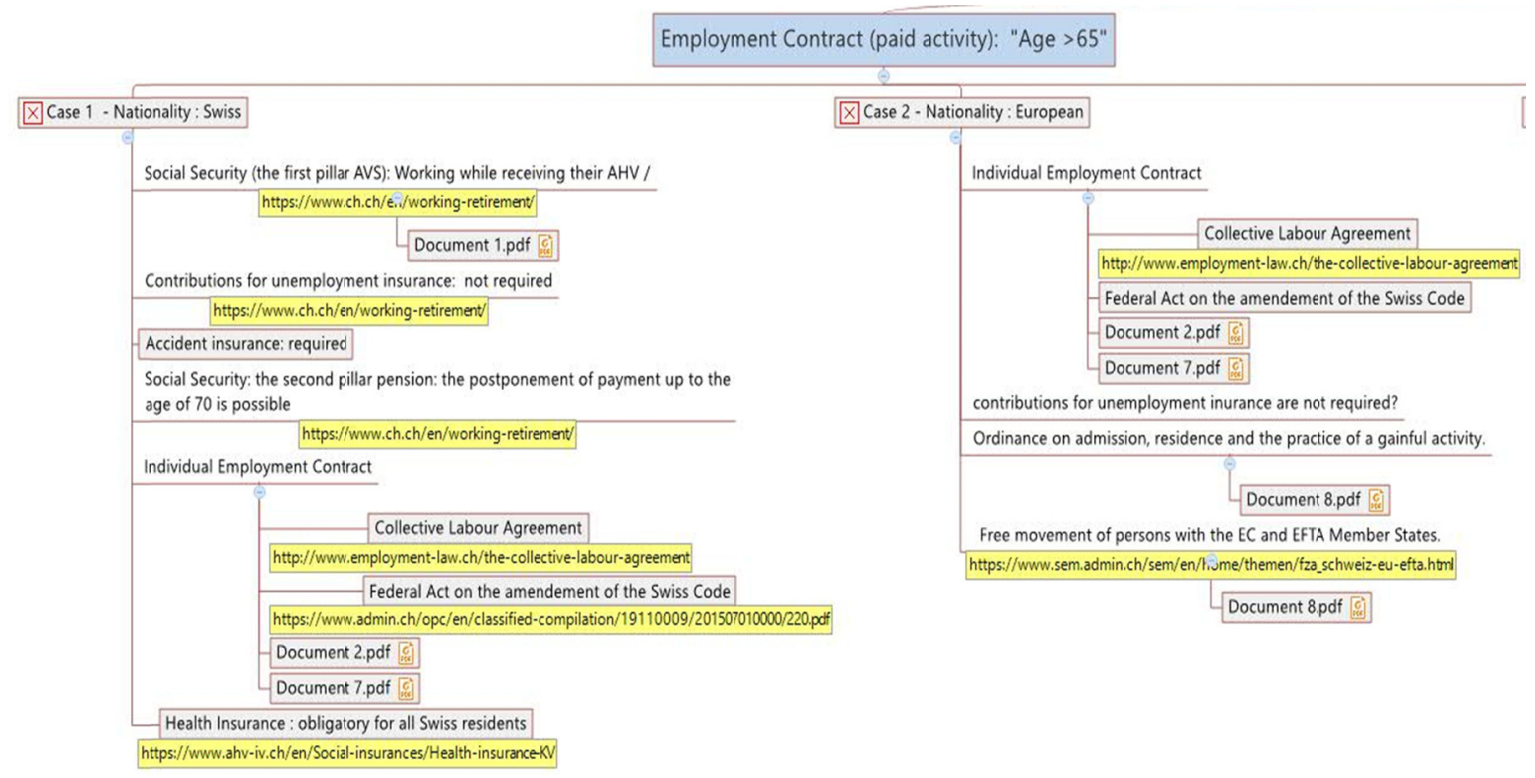

Figure 8. Situations describing the legal constraints regarding employment and post-retirement activities 


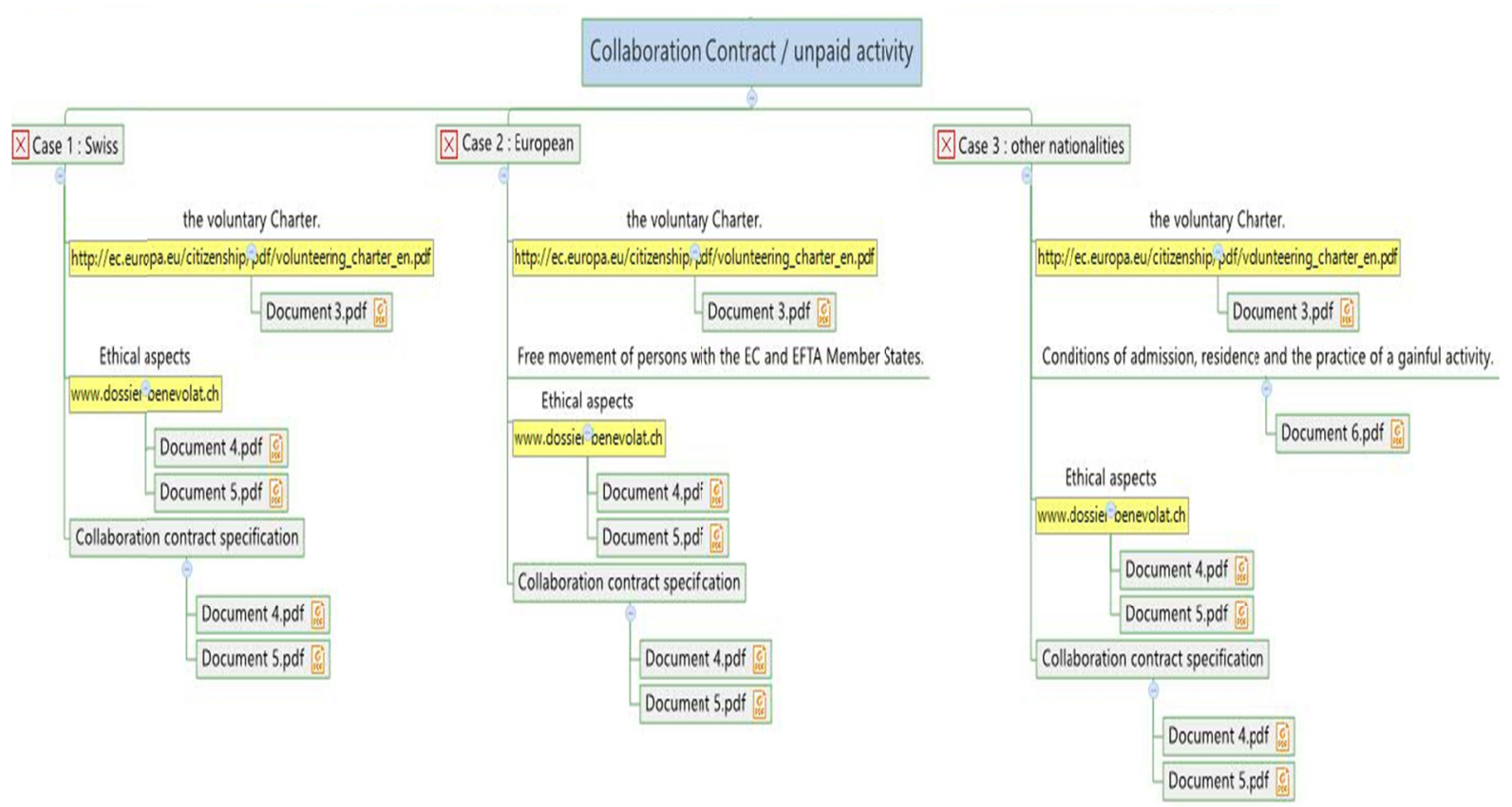

Figure 9. Situations describing the legal constraints regarding the volunteering activities.

\section{Conclusion and Future Works}

The personalization process requires an intensive work in advance in order to fulfill the satisfaction of end-users of ICT platforms. The pre-defined set of legal information needs several implications of service engineers and legal officers. The importance of personalization of legal information comes from the fact that end-users of any ICT platform are able to make decisions in real time. This has an impact on work efficiency of the organizations, which use the ICT platform for their daily activity by affecting them on time saving, having a possibility of interacting with legal content, and providing an easy way of decision-making processes when the issue comes to consult legal and ethical issues.

Currently, we have developed this service, by using relational database (Note 11), in order to demonstrate that traditional architectures such as database management systems can be used for managing legal information.

Furthermore, we conclude that the personalization process requires a lot of effort and rigor research in order to have a clear impact on efficiency of an ICT platform, due to the fact that, defining the set of information, which could be used by the personalization service is a research challenge for legal officers and service engineers.

Our future work is characterized in two research fields. The first step is to develop the personalization service as an intelligent system. This system is able to self-manage several tasks. It will update the set of legal sources in an automatic way by crawling data from official government web sites (Note 12). Secondly, we will use text-processing techniques for selecting legal rules to use in a personalized way. We intend to develop this feature by using text- processing engines, which are based in key word relevance, e.g. Apache Lucene (Note 13). This will give a powerful way of managing legal and ethical information in real time, while combining with first step.

\section{Acknowledgments}

This research is funded by the European Union in the Senior project of the Ambient Assisted Living Joint Program. The authors also gratefully acknowledge the comment and support provided by the coordinator and consortium partners of this project.

\section{References}

Adomavicius, G., \& Alexander T. (2005). Personalization technologies: A process-oriented perspective. Communications of the ACM48.10,83-90.https://doi.org/10.1007/s11576-006-0098-7

Bench-Capon, T. J., \& Visser, P. R. (1997). Ontologies in legal information systems.In Proceedings of the Sixth Int'l Conference of Artificial Intelligence and Law (ICAIL'97)(Melbourne, Australia) (pp. 132-141). 
Bing, J. (1984). Legal Information Retrieval.

Bratcher, R., Farrell, J. J., Stevens, K. A., \& Vanderground, K. W (2005). Ethical and Legal Issues.

Buecker, A., Ashley, P., Borrett, M., Lu, M., Muppidi, S., Readshaw, N. (2008). UnderstandingSOA Security Design and Implementation. IBM Redbooks. Information Communications Technology for Development. Retrieved from http://live.worldbank.org/information-communications-technology-development

Data Layer Guidelines (2016). Retrieved from https://msdn.microsoft.com/en-us/library/ee658127.aspx

De Ville, B., \& Neville, P. (2013). Decision Trees for Analytics Using SAS Enterprise Miner. SAS Institute.

Dini, L., Peters, W., Liebwald, D., Schweighofer, E., Mommers, L., \& Voermans, W. (2005, June). Cross-lingual legal information retrieval using a WordNet architecture. In Proceedings of the 10th international conference on Artificial intelligence and law (163-167). ACM.https://doi.org/10.1145/1165485.1165510

Dutta, R., \& Zachariah, J. (2002). U.S. Patent No. 6,501,421. Washington, DC: U.S. Patent and Trademark Office.

Fernandez, A., Polleres, A., \& Ossowski, S. (2007, November).Towards fine-grained service matchmaking by using concept similarity. In Proceedings of the 2007 International Conference on Service Matchmaking and Resource Retrieval in the Semantic Web-Volume 243 (pp. 27-31). Retrieved fromhttp://CEUR-WS. org

Gómez-Pérez, A., Ortiz-Rodríguez, F., \& Villazón-Terrazas, B. (2006, May). Ontology-based legal information retrieval to improve the information access in e-government. In Proceedings of the 15th international conference on World Wide Web (pp. 1007-1008). ACM. https://doi.org/10.1145/1135777.1135988

Hagen, P., Manning, H., \& Souza, R. (1999). Smart personalization. Forrester Research, Cambridge, MA.

Imeri, A., \& Khadraoui, A. (2015). The implementation of compliance: legal and ethical aspects into ICT platforms.International Conference (IACETI), Paris, France.

Imeri, A., Khadraoui, A., Rifaut, A., \& Nicolas, D. (2016). The new strategy to develop scenarios in compliance with legal and ethical issues. ACSIJ,5(2),73-82.

Mingers, J., \& Walsham, G. (2010). Toward ethical information systems: the contribution of discourse ethics. Mis Quarterly, 34(4), 833-854.

Mitchell, T. (1997). Machine Learning. MacGraw-Hill Companies. Inc, 1, 997.

Quinlan, J. R. (1986). Induction of decision trees. Machine learning, 1(1), 81-106.https://doi.org/10.1007/bf00116251

Rose, D. E., \& Belew, R. K. (1989, May). Legal information retrieval a hybrid approach. In Proceedings of the 2nd international conference on Artificial intelligence and law (pp. 138-146). ACM.https://doi.org/10.1145/74014.74033

Shazia S., \& Governatori, G. (2010). Managing regulatory compliance in business processes. Handbook on Business Process Management 2. Springer Berlin Heidelberg, 159-175. https://doi.org/10.1007/978-3-642-45103-4_11

Turki, S., \& Bjekovic-Obradovic, M. (2010, February). Compliance in e-government service engineering: State-of-the-art. In International Conference on Exploring Services Science (pp. 270-275). Springer Berlin Heidelberg. https://doi.org/10.1007/978-3-642-14319-9_23

Uluocha, A., \& Mabawonku, I. (2014). Legal Information Resources Availability and Utilisation as Determinants of Law Lecturers Research Productivity in Nigerian universities. Legal Information, 4(9).

Victor, M. B. (2001). Interpreting a decision tree analysis of a lawsuit.

Von Alan, R. H., March, S. T., Park, J., \& Ram, S. (2004). Design science in information systems research. MIS quarterly, 28(1), 75-105.

Yearwood, J., \& Stranieri, A. (1999, June). The integration of retrieval, reasoning and drafting for refugee law: a third generation legal knowledge based system. In Proceedings of the 7th international conference on Artificial intelligence and law (pp. 117-125). ACM. https://doi.org/10.1145/323706.323724

Zeleznikow, J. (2000). Building Decision Support Systems in Discretionary Legal Domains. International Review of Law, Computers \& Technology, 14(3), 341-356. https://doi.org/10.1080/713673368

Zeleznikow, J., \& Hunter, D. (1994). Building Intelligent Legal Information Systems: representation and reasoning in law (No. 13). Kluwer Law and Taxation Publishers. 


\section{Notes}

Note 1 The term of service scenarios is refered in the context of business processes.

Note 2 "Information and communications technologies (ICT) are distribution platformsfor providing public and private services, such as market information, financial services, education and health services", etc.. (Information Communications Technology for Development).

Note 3 Legal and ethical information are issues of rights based on the legal frameworks (Bratcher, Farrell, Stevens\& Vanderground, 2005).

Note 4 Any official document that contains legal or ethical information (ethical principles).

Note 5 Matchmaking is process of matching between two or more objects (Fernandez, Polleres\& Ossowski, 2007).

Note 6 "Personalization is the ability to provide content and services that are tailored to individuals basedon knowledge about their preferences and behavior" (Hagen, Manning \& Souza, 1999).

Note 7 http://www.employment-law.ch/the-collective-labour-agreement

Note 8 https://www.admin.ch/opc/fr/classified-compilation/19640049/index.html

Note 9 https://www.admin.ch/opc/fr/classified-compilation/20000832/index.html

Note $10 \mathrm{http} / / /$ ec.europa.eu/citizenship/pdf/volunteering_charter_en.pdf

Note 11 Microsoft SQL Server Developer Edition:

https://blogs.technet.microsoft.com/dataplatforminsider/2016/03/31/microsoft-sql-server-developer-edition-is-no w-free/

Note 12 e.g. an official web site: https://www.ch.ch/en/

Note $13 \mathrm{http}: / /$ lucene.apache.org/core/

\section{Copyrights}

Copyright for this article is retained by the author(s), with first publication rights granted to the journal.

This is an open-access article distributed under the terms and conditions of the Creative Commons Attribution license (http://creativecommons.org/licenses/by/4.0/). 